\title{
MOOC Construction and Application based on the Cloud Platform of Higher Vocational Colleges
}

\author{
Song Xiao-li, Zeng Jian-ming \\ Jiangxi Modern Polytechnic College
}

\begin{abstract}
Since rising the boom around the world in 2012, MOOC has experienced the development of more than two years. The MOOC research of the society from all walks of life has gradually return to rational from fever. Although some scholars criticize MOOC exists the problems, such as high dropout rates, being lack of learning support services, MOOC still has attracted numerous learners from around the world with its good user experience. MOOC is a technical tool, rather than a solution. So MOOC cannot be expected to change college and universities. MOOC can bring transformative effects in colleges and universities, which is based on its mix teaching mode and its revealing the diversity of students learning needs. So this paper discusses the mix teaching mode and curriculum construction diversity of colleges and universities based on MOOC.
\end{abstract}

Keywords-MOOC; Teaching model; Cloud platform; Higher colleges and universities

\section{INTRODUCTION}

Entering the 21st century, the remote education which takes modern information technology and media facilities as the carrier is paid large attention to by the world. From Web1.0 era which is based on resources present and propagation, one-way transmission, static display structured knowledge and takes teachers as the main body learning mode to Web2.0 era which is based on the theory of constructivism with multiple roles of learns, focuses on knowledge circulation without organization, unstructured scattered and network transmission, and is based on common construction and interaction, the change and use of information technology has played a key role to the development of remote education. Blog, Wiki, RSS, P2P, SNS and other Internet technology is gradually used in remote education. The application of information technology promotes the development of the network learning in digital age.

With the development of cloud computing, 3G communications, mobile computing and other technologies, mobile learning, U-learning and other applications are also changing the remote education mode which is based on the Internet. Cloud computing technology breaks the traditional mode and brings brand-new idea for the development of remote education. Cloud era also boosts the development of network education mode. As a kind of typical network course mode, MOOC draws widely attention.

Based on the problems that the local application-oriented colleges have weak teacher strength, limited investment and are difficult to improve the teaching quality and level of the computer courses, this paper puts forward computer courses teaching reform based on MOOC and carries out implementation. The scheme argues from the aspect of the colleges situation and carries on MOOC reform from course system, course teaching, practice teaching and evaluation four aspects.

\section{MOOC COURSE MODE}

MOOC, which is also called Massive Open Online Course, is a new type of curriculum pattern in the open education field in recent years. It is free open online courses for the social public. It is made up of the open and large-scale courses on the Internet issued by a number of individuals or organizations which have sharing and cooperation spirits and willing to enhance the knowledge. MOOC has the characteristics of the massive learning resources, large-scale distributed learning partners, diversity of distributed network learning support services, openness, self-organization and sociality. MOOC is not to collect, but to connect the teachers and learners all over 
the world by a common approach or subject. It originates from resource release, learning management system and the course development mode which is to combine the learning management system with more network resources.

MOOC appears under the background that the Internet technology has been successfully applied in education, the concept of open education has been accepted by the society and the social learning has become a main learning way. The appearance of the course mode has drawn widespread attention of the remote education, the open education and even the entire education and training industry. Over the past one year, many important innovation projects apply MOOC, including Udacity, Coursera, Khan Acadmy, edX, etc. Dozens of the world famous universities also included.

\section{THE CONSTRUCTION OF MOOC TEACHING SYSTEM BASED ON CLOUD PLATFORM OF COLLEGES}

As the key of MOOC course, campus MOOC cloud platform is needed in MOOC course of colleges and universities, which includes mass MOOC resource database, MOOC course management, MOOC learning platform and tools, MOOC courses personalized push and multiple MOOC terminal access. Mass MOOC resource database includes course software library and video library of MOOC courses, high quality courses, video conference and all kinds of material libraries. MOOC course management includes upload, download, learning, evaluation and discussion of MOOC courses, and the classification and sorting of MOOC courses, the search of MOOC courses, the smart automatic answering system, the virtual laboratory and online test of MOOC courses. During MOOC learning, teachers and students need to communicate and interact, which needs the corresponding communication tools which commonly are Wiki groups, BBS, blog, learning space, virtual classroom, timely communication, collaboration platform, BBS and so on. Personalized push of MOOC course refers to push courses to users which are suitable for their learning requirements according to their learning habits and Internet information. Multiple MOOC terminal access refers that users can use $\mathrm{PC}, \mathrm{PAD}$, television, mobile phone and other devices to login platform for learning. The construction of college MOOC cloud platform can create a integration and personalized learning environment for students and realize the cloud storage and management of mass resources, which is a way to make resource move and make searching for resource become pushing information, which is shown in Fig.1.

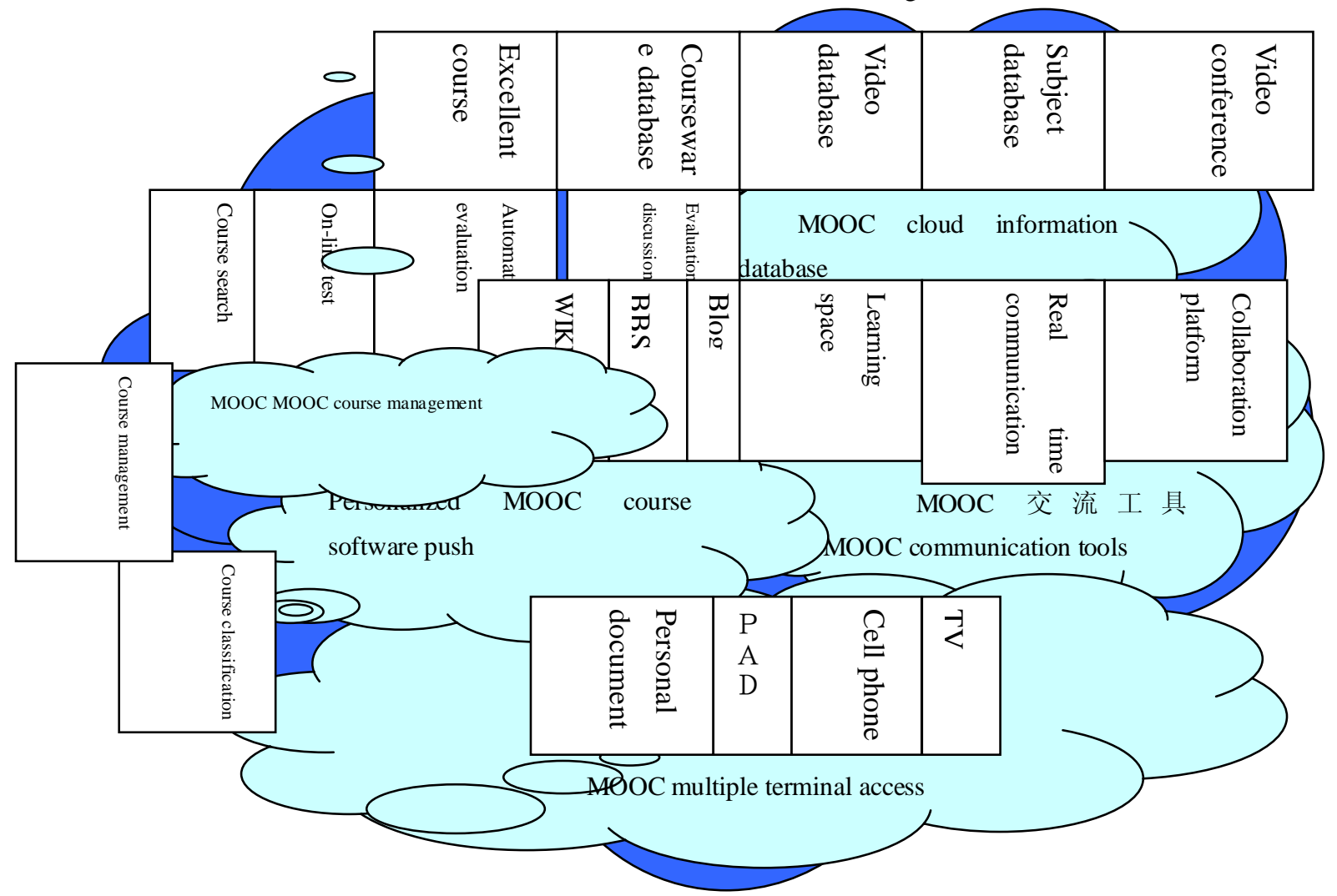

Figure 1.The design of MOOC cloud platform of colleges and universities 


\section{IMPLEMENTATION AND EFFECT OF MOOC}

\section{TEACHING REFORM}

Now with the help of cloud space, MOOC teaching reform of the computer course has been carried out. There are complete 451 resources of $\mathrm{C}$ language curriculum cloud space, which continues to increase. Because the costs are lower and have elasticity, cloud space is suitable for the teacher and students of the local undergraduate colleges and universities to set up their own MOOC teaching platforms. During the period of construction, teachers' workload is bigger, but through the subsequent application, the working pressure can be alleviated. Teachers can issue teaching resources, prepare lessons, arrange homework, correct student's paper, arrange experiments, correct experiments, arrange curriculum design and grade curriculum design through the clout space, while students can learn, interact, finish homework, submit experiment and the curriculum design. In a word, through the cloud space, students can learn $\mathrm{C}$ language courses with more convenience, interests and pressure, while teachers can organize teaching, management and examination and other teaching activities more easily, inexpensively and interactively.

\section{CONCLUSION}

Since the large rise of MOOC, it has been more than two years. The teaching mode has gradually tend to be stable. It can be seen through the element analysis of MOOC teaching model in this paper the great potential of MOOC in teaching reform and informatization construction in colleges and universities. In the early days of MOOC, there were scholars who had high expectations of its and thought it can bring new changes to higher education reform. Although it is unable to verify the effect of its influence, it is worth trying to participate in. During the whole process of the research of MOOC, the author experienced a great learning experience. The author believes that MOOC can play a great role in promoting the construction of lifelong learning society. Whether it can continue to develop in the future mainly depends on its operation. Whether it can reduce the cost of certification certificate, how to get the certificate and the mutual recognition of credits in colleges and universities and how to build a more perfect student electronic files are still needed to be researched.

\section{ACKNOWLEDGEMENTS}

This work was supported by

Jiangxi province colleges and universities teaching reform research topic: MOOC construction in higher vocational colleges based on the cloud platform and application (No.JXJG-14-46-10)

\section{REFERENCES}

[1 ]Mackness, Jenny, F. J. M. Sui, and R. Williams. "The Ideals and Reality of Participating in a MOOC." Education (2010).

[2 ]Breslow L, Pritchard D E, Deboer J, et al. Studying Learning in the Worldwide Classroom Research into edX's First MOOC.[J]. Research \& Practice in Assessment, 2013, 8:13-25.

[3] Yoon K, Parkin G, Rheingold A L. A reinvestigation of the molecular structures of cis-mer-MoOCl2(PR3)3: do bond-stretch isomers really exist?[J]. Journal of the American Chemical Society, 1991, 113(4):1437-1438.

[4] Bruff D O, Fisher D H, Mcewen K E, et al. Wrapping a MOOC: Student Perceptions of an Experiment in Blended Learning[J]. Journal of Online Learning \& Teaching, 2013.

[5] Haggard, S. (2013). The maturing of the mooc literature review of massive open online courses and other forms of online distance learning september 2013. Department for Business Innovation \& Skills.

[6] Christensen, G., Steinmetz, A., Alcorn, B., Bennett, A., Woods, D., \& Emanuel, E. J. (2013). The mooc phenomenon: who takes massive open online courses and why?. Social Science Electronic Publishing.

[7] Belanger Y, Thornton J. Bioelectricity: A Quantitative Approach---Duke University's First MOOC $[\mathrm{J}]$. Inorganic Materials, 2013, 38(2):522-526.

[8] Cross, Simon. "Evaluation of the OLDS MOOC curriculum design course: participant perspectives, expectations and experiences." Olds Mooc Project (2013).

[9] Creed-Dikeogu G, Clark C. Are You MOOC-ing Yet? A Review for Academic Libraries[J]. Kansas Library Association College \& University Libraries, 2013, 3.

[10] Guàrdia L, Maina M, Sangrà A. MOOC Design Principles. A Pedagogical Approach from the Learner's Perspective[J]. Elearning Papers, 2013, 33:1-6.

[11] Belanger, Yvonne, and J. Thornton. "Bioelectricity: A Quantitative Approach---Duke University's First MOOC." Inorganic Materials 38.2(2013):522-526.

[12] Alario-Hoyos C, Pérez-Sanagustín M, Delgado-Kloos C, et al Analysing the Impact of Built-In and External Social Tools in a MOOC on Educational Technologies[M] Scaling up Learning for Sustained Impact. Springer Berlin Heidelberg, 2013:5-18. 